\title{
Rupture of the Left Renal Fornix after Vaginal Repair of Postpartum Vesicovaginal Fistula
}

\author{
Fornixruptur der linken Niere nach vaginaler Fistelplastik zur Versorgung \\ einer postpartalen vesikovaginalen Rezidivfistel
}

Authors

Affiliations
R. Rendtorff ${ }^{1}$, H. H. Knispel ${ }^{2}$, R. Tunn ${ }^{1}$

${ }^{1}$ Deutsches Beckenbodenzentrum, Klinik für Urogynäkologie, St. Hedwig-Krankenhaus, Berlin

${ }^{2}$ Deutsches Beckenbodenzentrum, Klinik für Urologie, St. Hedwig-Krankenhaus, Berlin

\section{Key words \\ - urinary incontinence \\ - sonography \\ - vagina \\ Schlüsselwörter \\ - Harninkontinenz \\ - Ultraschall \\ - Vagina}

Deutschsprachige Zusatzinformationen online abrufbar unter: www.thieme-connect.de/ ejournals/toc/gebfra

$\begin{array}{lr}\text { received } & 17.1 .2014 \\ \text { revised } & 12.3 .2014 \\ \text { accepted } & 13.3 .2014\end{array}$

Bibliography

DOI http://dx.doi.org/

10.1055/s-0034-1368365

Geburtsh Frauenheilk 2014; 74 :

376-378 ๑ Georg Thieme

Verlag KG Stuttgart · New York . ISSN 0016-5751

\section{Correspondence}

Dr. Rosa Rendtorff, Dr. med.

St. Hedwig-Krankenhaus

Deutsches Beckenbodenzen-

trum, Klinik für Urogynäkologie

Große Hamburger Straße 5

10115 Berlin

Rosa.Rendtorff@gmail.com

\section{Abstract \\ $\nabla$}

Surgical repair of vesicovaginal fistulas carries a risk of postoperative obstruction of the upper urinary tract. In the case described here, a postoperative intramural edema led to urinary retention and subsequent rupture of the renal pelvis. This is a rare but typical urological emergency. If patients complain postoperatively of flank pain, ultrasound should be carried out promptly. If the findings are unclear (no urinary retention despite clinical symptoms), additional computed tomography should be performed to determine whether rupture of the fornix has occurred.

\section{Introduction}

Fornix rupture is rare but it constitutes a urological emergency. In most cases it is caused by the presence of ureteral or kidney stones at the distal end of the ureter [1]. Other causes include malignant diseases with compression of the urinary tract, trauma, and iatrogenic fornix rupture, for example after vaginal hysterectomy or radical prostatectomy. The etiology in many cases remains unclear [2]. In patients with acute colic, infusion excretory urography carries a substantial risk of fornix rupture due to the osmotic diuresis created by the contrast medium; infusion excretory urography is therefore usually contraindicated in these patients or should only be carried out after administration of spasmoanalgesics [1, 3]. As computed tomography with contrast medium administration is also associated with a risk of fornix rupture, the first step should consist of native computed tomography which, in many cases, will already suggest the diagnosis. Continuously increasing pressure can lead to distension,

\section{Zusammenfassung \\ $\nabla$}

Im Rahmen der operativen Korrektur vesikovaginaler Fisteln besteht das Risiko einer postoperativen Abflussbehinderung der oberen Harnwege. Eine wundödembedingte Einengung des intramuralen Ureters führte im vorliegenden Fall zum Harnstau mit Fornixruptur des Nierenbeckenkelchsystems. Es handelt sich hierbei um einen seltenen, aber typischen urologischen Notfall. Bei postoperativen Schmerzen im Bereich des Nierenlagers sollte daher frühzeitig die Nephrosonografie durchgeführt werden. Bei Befundunklarheit (fehlende Harnstauung bei klinischer Symptomatik) kann ergänzend eine Computertomografie durchgeführt werden, um eine Fornixruptur zeitnah zu objektivieren. followed by rupture of the renal pelvis and extravasation of urine into the perirenal area [4]. The renal pelvic calyx system is unable to withstand the increased internal pressure and ruptures at the point where the tissue is weakest [3]. This reduces pressure and has a nephroprotective effect $[2,3]$. Flank pain is the most typical symptom of urinary obstruction. The typical clinical sign of forniceal rupture is sudden diminution of pain due to the reduction of pressure [1]. Hematuria, nausea and vomiting, fever and inflammation parameters are common accompanying symptoms. Extravasation of urine into the perirenal tissue may be visible on sonography. The differential diagnosis includes urinoma, hematoma or abscess [4,5]. Native computed tomography can show urine leakage into the parapelvic tissue, which would indicate forniceal rupture. If native computed tomography does not provide sufficient evidence, i.v. administration of contrast medium can be used to confirm the suspected diagnosis $[2,3]$. In the first instance, treatment must focus on quickly relieving pressure. This can be 


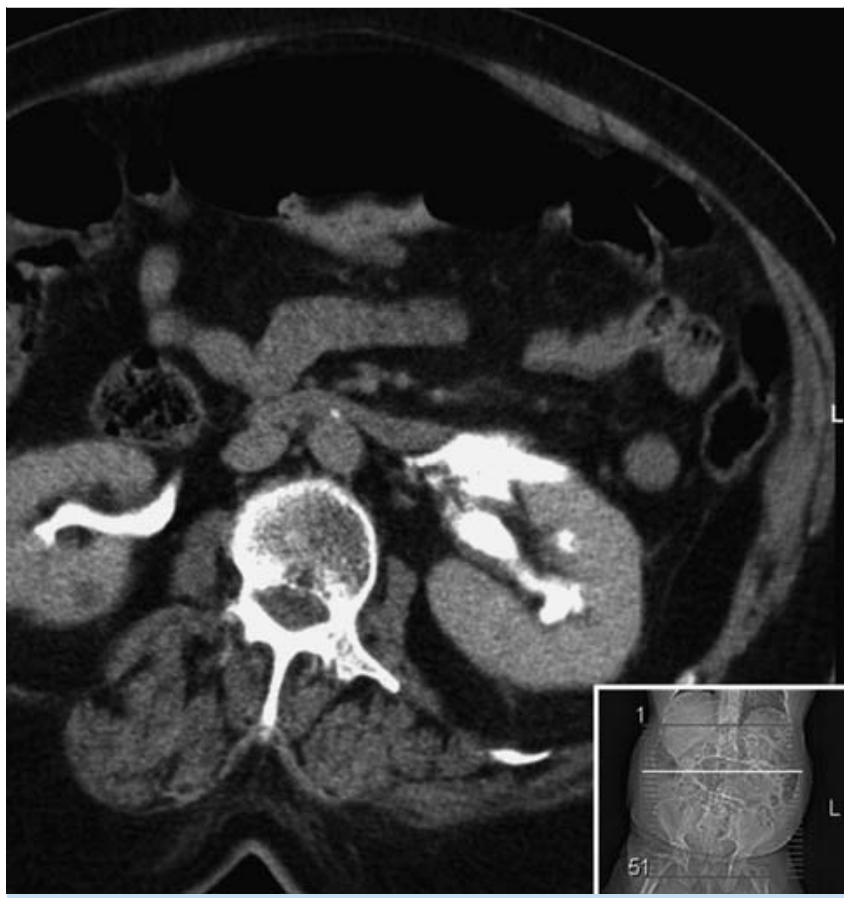

Fig. 1 Computed tomography: transverse section showing extravasation of contrast medium due to rupture of the left renal fornix.

achieved endoscopically, in most cases through placement of a ureteric stent. If this is not possible, percutaneous nephrostomy placement can be an alternative treatment; however, this procedure can be challenging if there is no urinary stasis. Antibiotic treatment should also be initiated, although no standards have been defined yet for antibiotic therapy.

\section{Case Report}

$\nabla$

A 73-year-old patient presented with complete urinary incontinence which had existed for almost 40 years. Her medical history showed that incontinence had persisted since vaginal delivery 40 years previously; a failed attempt at fistula closure was carried out in 1986 as there was already a suspicion of postpartum vesicovaginal fistula. The patient had a secondary diagnosis of arterial hypertension and possible myocardial infarction about 4 years ago.

Vaginal examination showed a narrow vagina with a fistula measuring around $1 \mathrm{~cm}$ in the anterior vaginal vault which discharged urine. The uterus and adnexa were sonographically unremarkable. Retrograde cystoscopy with visualization of the urinary tract was carried out, during which a fistula, measuring approximately $1 \mathrm{~cm}$, was noted at the transition between bladder floor and posterior bladder wall. Bladder filling was almost impossible due to the limited bladder capacity. Ureters and renal pelvic calyx system were found to be normal on both sides. Computed tomography was highly suspicious for vesicovaginal fistula with air bubbles in the bladder and a fluid-filled vagina.

Vaginal closure of the fistula was done using the method of Sims and Simon [6,7]. At the start of the procedure, the fistula was probed from the vaginal side using a blocked indwelling catheter, the margins around the fistula channel were circumcised, and the vaginal wall was mobilized. The bladder wall was closed but

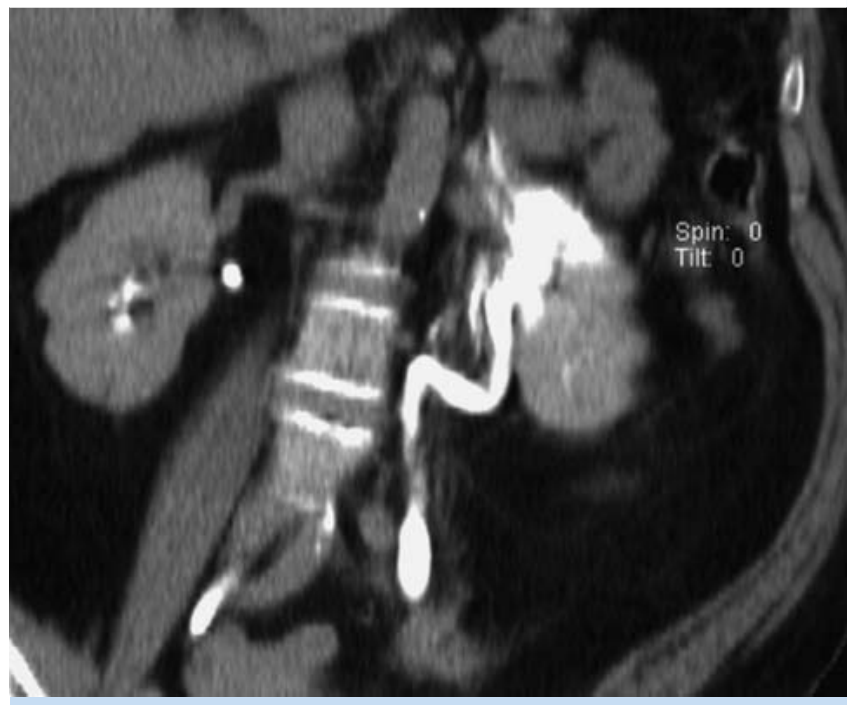

Fig. 2 Computed tomography: frontal section showing extravasation of contrast medium due to rupture of the left renal fornix.

the urothelium was spared; the colpotomy was closed and a transurethral indwelling catheter placed and left in situ for a period of 3 weeks. Histological examination of the tissue obtained from the fistula channel found chronic glandular and cystic cystitis.

The patient already complained of diffuse pain in the abdomen and left renal bed on the first day postoperatively. No urinary stasis was found on subsequent renal sonography; the only finding was prominent renal pelvic calyx systems on both sides. As the pain persisted and inflammatory parameters started to increase, additional diagnostic tests were carried out on the 2nd postoperative day. Computed tomography with i.v. administration of contrast medium showed left renal rupture of the fornix as well as grade $\mathrm{II}^{\circ}$ urinary obstruction on the left side and grade $\mathrm{I}^{\circ}$ urinary obstruction on the right side ( Figs. 1 and 2). After retrograde stenting failed, a percutaneous renal stoma was placed on the left side on the 2 nd postoperative day. On the 4th postoperative day, antegrade insertion of a double-J catheter was done on the left side without difficulty and without encountering any significant stenosis. This allowed the renal stoma to be removed and the patient could be discharged.

Ten weeks after the procedure the patient reported frequent, strong urge to urinate with a micturition frequency of around once per hour. The patient rarely noted unintentional loss of urine, and now only required small pads. The patient received regular medication consisting of $5 \mathrm{mg}$ solifenacin, which helped to improve the symptoms of urinary urgency over time.

\section{Discussion}

\section{$\nabla$}

Rupture of the fornix is a rare but typical urological emergency, which is associated with sepsis or even loss of renal function [1, $3,5]$. There are no predictive values which can be used to focus attention on high-risk patients. Because forniceal rupture is rare, many doctors have no experience of this situation in routine clinical practice, and making the correct diagnosis is complicated by the fact that pain symptoms will improve abruptly after rupture and the resulting absence of urinary stasis. The case presented 
here shows that even short-term obstruction of urinary flow caused by wound edema can lead to fornix rupture. This shows that even short-term symptoms occurring postoperatively need to be investigated to rule out urinary obstruction. If the findings on nephrosonography do not correlate with the clinical symptoms, then further diagnostic investigation using computed tomography is required [2]. Prompt drainage of urine on the affected side is essential for the subsequent course of disease [8]. Retrograde ureteral stenting is preferable to placement of a nephrostomy tube, particularly as placement of a nephrostomy catheter is technically tricky in the non-obstructed kidney. Preoperative stenting is recommended when treating fistulas close to the ureter as it can prevent postoperative urinary obstruction. The second conclusion to be drawn from this case report is that surgical repair of vesicovaginal fistulas is possible even after many years. Fistula closure after 40 years, as described in the case reported here, requires suitable postoperative management which takes account of the bladder dysfunction caused by the longstanding bladder inactivation. It is important to weigh the risks and benefits of such an operation at the time of planning surgery. Urinary incontinence can persist even after successful fistula closure due to urge incontinence, lack of bladder capacity, or age-related stress incontinence, meaning the longed for improvement in the patient's quality of life may fail to materialize. Postoperative bladder training, physiotherapy, anticholinergics and allowing sufficient time for convalescence are important factors in the postoperative management of patients.
In summary, postoperative pain occurring in the area around the kidneys is a serious symptom. Early postoperative nephrosonography augmented by computed tomography, if required, is essential to obtain an early diagnosis of forniceal rupture.

\section{Conflict of Interest}

None.

\section{References}

1 Doehn C, Fiola L, Peter $M$ et al. Outcome analysis of fornix ruptures in 162 consecutive patients. J Endourol 2010; 24: 1869-1873

2 Gershman B, Kulkarni N, Sahani D et al. Causes of renal forniceal rupture. BJU International 2011; 108: 1909-1912

3 Breun H, Csapo Z, Sigel A. Fornix-Ruptur - Überprüfung der Pathophysiologie und der Klinik. Urologe [A] 1989; 28: 329-333

4 Klasen J, Rabenalt $R$, Heinen $W$ et al. Harnleitersteinbedingte Fornixruptur in der Schwangerschaft. Urologe 2010; 49: 1172-1175

5 You JS, Chung YE, Lee JY et al. The spontaneous rupture of the renal fornix caused by obstructive nephropathy. J Emerg Med 2012; 43: 488489

6 Hirsch HA, Käser O, Iklé FA. Atlas of gynecologic Surgery. Stuttgart: Thieme; 1997: 587-591

7 Tunn R, Hanzal E, Perucchini D. Urogynäkologie in Praxis und Klinik. Berlin: de Gruyter; 2010: 336-339

8 Kalafatis P, Zougkas K, Petas A. Primary ureteroscopic treatment for obstructive ureteral stone-causing fornix rupture. Int J Urol 2004; 11 : 1058-1064 